\title{
Communication
}

\section{Dynamic Sensing of Localized Corrosion at the Metal/Solution Interface}

\author{
Wei Li ${ }^{1}$, Boyu Yuan ${ }^{1,2, *}$, Chao Wang ${ }^{3}$, Liang $\mathrm{Li}^{3}$ and Shenhao Chen ${ }^{4}$
}

1 School of Mechanical and Electrical Engineering, China University of Mining and Technology, Xuzhou 221116, China

2 School of Physics and Electronics Engineering, Jiangsu Normal University, Xuzhou 221116, China

3 Department of Chemistry, Jiangsu Normal University, Xuzhou 221116, China

4 Department of Chemistry, Shandong University, Jinan 250100, China

* Author to whom correspondence should be addressed; E-Mail: isecmee@cumt.edu.cn;

Tel./Fax: +86-516-8359-0798.

Received: 15 February 2012; in revised form: 10 April 2012 / Accepted: 11 April 2012 /

Published: 18 April 2012

\begin{abstract}
A Mach-Zehnder interferometer is employed to detect localized corrosion at the metal/solution interface in the potentiodynamic sweep of the iron electrode in solutions. During the electrochemical reactions, local variations of the electrolyte's refractive index, which correlate with the concentration of dissolved species, change the optical path length (OPL) of the object beam when the beam passes through the electrolyte. The distribution of the OPL difference was obtained to present the concentration change of the metal ions visually, which enable direct evidence of corrosion processes. The OPL difference distribution shows localized and general corrosion during the anodic dissolution of the iron electrode in solutions with and without chloride ions, respectively. This method provides an approach for dynamic detection of localized corrosion at the metal/solution interface.
\end{abstract}

Keyword: localized corrosion; interfaces; Mach-Zehnder interferometer

\section{Introduction}

Localized corrosion, a serious problem in industries for it often causes catastrophic failures in engineering structures, normally results from the breakdown of passive films in aggressive environments, especially in media containing chloride ions. Localized corrosion includes various types 
of corrosion phenomena such as pitting, crevice corrosion, stress corrosion cracking and corrosion fatigue [1]. In contrast to general corrosion, whose rate will normally be predictable from vast experience, localized corrosion tends to proceed at a high rate of metal dissolution from the local area. The investigation of localized corrosion is of particular interest and importance in many scientific and technological applications [2-11]. Although a lot of effort has been made to understand its mechanisms and to prevent its occurrence, localized corrosion is still a common cause of failures in seawater desalination units, gas and oil refining equipment, water-cooling systems and steel reinforced concrete structures [12].

Many techniques have been used to study the localized corrosion caused by chloride ions, most of which are involved direct current (DC) polarization [13,14], electrochemical noise (EN) technique [15,16], X-ray spectroscopy [17-19], electrochemical impedance spectroscopy (EIS) [19-22], scanning electrochemical microscopy (SECM) [23-25] and scanning vibrating electrode technique (SVET) [26-28]. DC polarization is probably the most used electrochemical technique in corrosion, where the majority of the achievements on localized corrosion were obtained. In recent decades the others were usually utilized in combination with DC polarization to study localized corrosion. All of these techniques have yielded considerable insights into localized corrosion processes. As the dynamic processes are not fully understood, more experimental methods are required for in situ observation of localized corrosion at the metal/solution interface.

Optical interferometry can provide quantitative measurement of the optical path length (OPL) distribution that allows transparent samples to be described with a diffraction-limited transverse resolution and a sub-wavelength axial accuracy [29,30]. The main advantages of this full-field optical method are: nondestructive working principle, fast response and the advanced performance of the systems [31]. With those merits, corrosion scientists have paid much attention to develop and utilize optical interferometric methods to study localized corrosion processes [6,32-34]. Punckt et al. employed ellipsomicroscopy for surface imaging (EMSI) and specially adapted high resolution contrast-enhanced optical microscopy to visualize the onset of pitting corrosion directly in the solution [6]. Habib used holographic interferometry to study the local corrosion of carbon steel in seawater [32]. Wang explored the digital speckle pattern interferometry to investigate pitting corrosion processes of metal [33]. Tada applied Mach-Zehnder interferometry and shadowgraphy to investigate the concentration field of $\mathrm{Zn}^{2+}$ during galvanic corrosion of a $\mathrm{Zn} / \mathrm{Steel}$ couple successfully [34]. In situ observations have been carried out in our laboratory using digital holographic methods to study the dynamic processes of electrochemical reactions [10,11,35-40]. It has been proved to be effective in investigating the dynamic processes of the electrochemical reactions at the electrode/electrolyte interface.

In this paper, a Mach-Zehnder interferometer is employed to visualize localized corrosion processes at the metal/solution interface during anodic dissolution of iron in $\mathrm{Na}_{2} \mathrm{SO}_{4}$ and $\mathrm{NaCl}$ solutions in combination with linear sweep voltammetry. During the electrochemical processes of the iron electrode in the presence of chloride ions, the local area of the electrode dissolved as metal ions firstly, which led to high local concentration of the solution at the area. The distributions of the OPL difference are presented to observe the processes visually. 


\section{Experimental}

Voltammetric Measurements. As shown in Figure 1, the electrochemical cell contains a three-electrode system. The cell is made up of optical glass and its volume is about $100 \mathrm{~mL}$. The iron electrode (Puratronic, Alfa Aesar, 99.99\%) with a diameter of $2 \mathrm{~mm}$ served as the working electrode. It was sealed in a glass tube, with one end of tube sanded flat to expose the electrode. The counter electrode was a large sheet of platinum $(0.8 \mathrm{~cm} \times 2.8 \mathrm{~cm})$. The reference electrode was a saturated calomel electrode (SCE) with a Luggin capillary, whose end is set near the surface of the iron electrode. All potentials reported here were with respect to SCE. Before each experiment, the iron electrode was mechanically abraded with \#1500 and \#3000 emery papers to a mirror-like brightness and then cleaned by alcohol and three triply distilled water in an ultrasonic bath. The electrolytes were $0.5 \mathrm{M} \mathrm{NaCl}$ solution and $0.5 \mathrm{M} \mathrm{Na}_{2} \mathrm{SO}_{4}$ solution. All solutions were prepared from reagents of analytical grade and triply distilled water. Voltammetric measurements were performed by means of CHI660B electrochemical station at room temperature. Prior to potentiodynamic polarization experiments, the open circuit potential (OCP) was recorded for $10 \mathrm{~min}$. The positive sweep of potential was carried out at the rate of $10 \mathrm{mV} \cdot \mathrm{s}^{-1}$ in each experiment.

Figure 1. Schematic diagram of the electrochemical cell. R, reference electrode; $\mathrm{W}$, working electrode; $\mathrm{C}$, counter electrode.

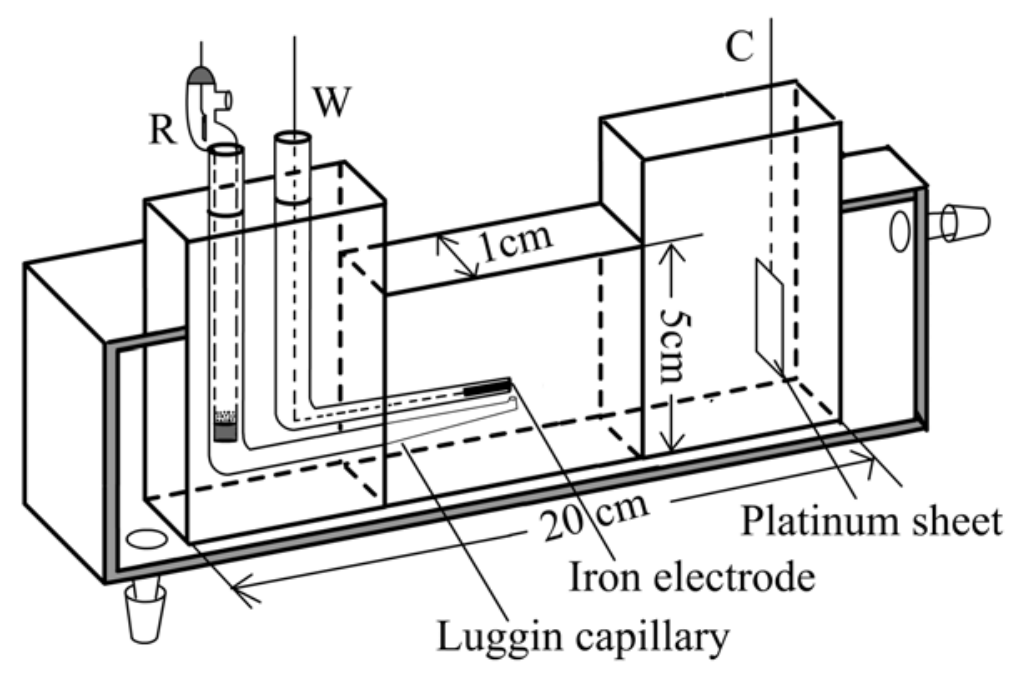

Optical system. The experimental setup of the Mach-Zehnder interferometer is illustrated in Figure 2. The beam of a He-Ne laser with a wavelength of $632.8 \mathrm{~nm}$ was split into two beams, a reference wave and an object wave by a beam-splitter. Each beam was enlarged to a diameter of $50 \mathrm{~mm}$ by a beam expander including a spatial filter. The beam that carried the information of the metal/solution was combined with the reference wave by a beam-splitter cube and then recorded by a CCD sensor. A digital camera, the Sony DSR-PD150P, was used to record the dynamical process. It has a $1 / 3$ inch sensor which can provide a progressive scanning format with $720 \times 576$ effective pixels. The interferograms corresponding with various states of the metal/solution interface were imaged by the camera. Ulead VideoStudio 8.0 software was used to capture the video signal. The videos were 
stored in the computer as AVI (audio visual interleaved) files at up to 25 frames per seconds. The distributions of the OPL difference at any intervals in the dynamic process can be obtained from the corresponding interferograms by various phase abstraction methods. In our measurement, Fourier method was employed to obtain the OPL information from the interferograms so as to achieve consecutive calculation and reduce the noise of the system. Since the object wave hits a circular sample from the side, the observed area (the gray area) is a changing sample area, as shown in Figure 3. It has been corrected during image processing.

Figure 2. Experimental setup of the Mach-Zehnder interferometer. M, mirror; BS, beam splitter; SF, spatial filter; L1, L2 and L3, lens; O, the electrochemical cell.

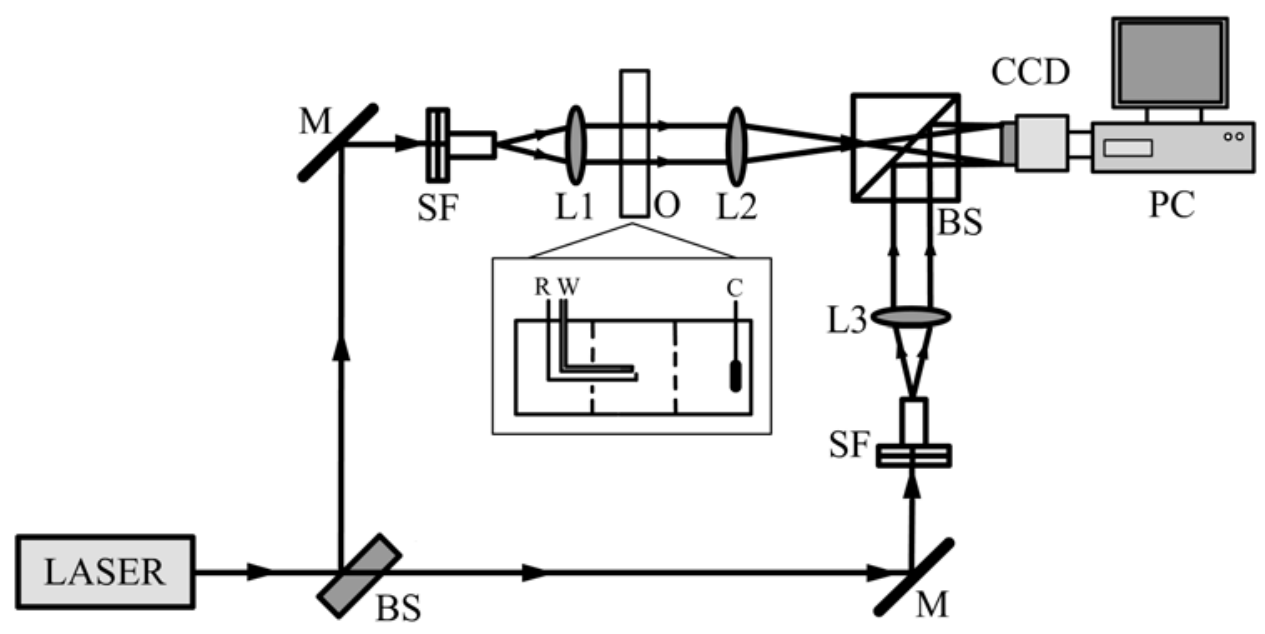

Figure 3. The object wave passing though the electrode surface. The $X$ axis is in horizontal direction from the electrode surface toward the bulk electrolyte while the $Y$ axis in vertical direction is parallel to the surface of electrode.

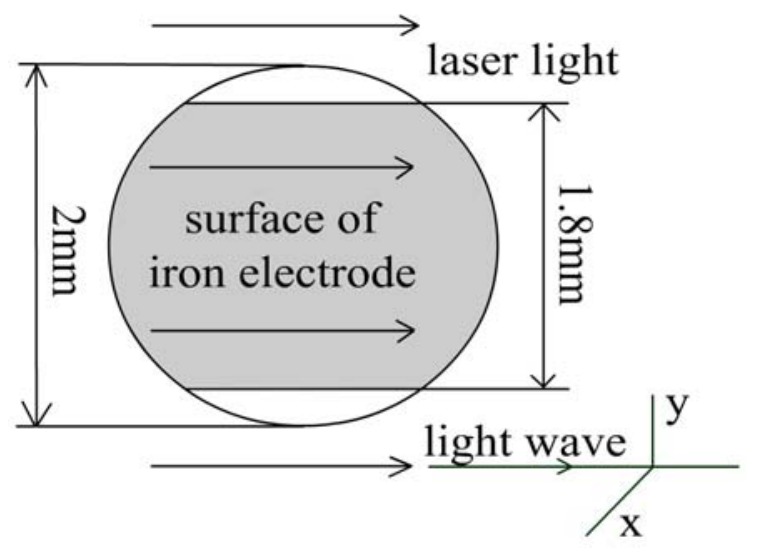

\section{Mathematical Model}

During the electrochemical reactions, the anodic dissolution of metals resulted in the increase of concentration of the metal ions, which leaded to a refractive index variation of the solution at the metal/solution interface. The present experiment is based on the fact that the changes of the refractive 
index in the solution caused by the electrochemical reactions are associated with the OPL of the object wave when it goes through the solution.

If $n_{2}$ and $n_{1}$ are used to denote the refractive index after and before the reaction in the Mach-Zehnder interferometer, then [41]:

$$
\Delta L_{(x, y)}=\int\left(n_{2}-n_{1}\right) \mathrm{d} l=\int \Delta n_{(x, y)} \mathrm{d} l
$$

where $\Delta L_{(x, y)}$ means the difference of the OPL of the object wave; $l$ means the distance where the object wave passes through.

$\Delta L_{(x, y)}$ can be obtained by the phase difference of the object wave [42]:

$$
\Delta L_{(x, y)}=\left[\Delta \phi_{(x, y)} / 2 \pi\right] \lambda
$$

where $\Delta \varnothing_{(x, y)}$ means the phase difference of the object wave; $\lambda$ is the wavelength of the laser used.

In our measurement, Fourier analysis method is employed to extract $\Delta \emptyset_{(x, y)}$ from the interferograms. The recording is made with identical conditions of illumination, the intensity $I_{(x, y, t)}$ recorded on the hologram at time $t$ during the reactions is given by $[36,43]$ :

$$
I(x, y, t)=a(x, y)+b(x, y) \cos \left[2 \pi f_{0} x+\phi(x, y, t)\right]
$$

where $a(x, y)$ and $b(x, y)$ are the background and modulation terms, respectively; $f_{0}$ is a spatial carrier frequency and the phase $\varnothing(x, y, t)$ contains the desired information at different time. It can be also written in the following form:

$$
I(x, y, t)=a(x, y)+\frac{1}{2} b(x, y) \exp i\left[2 \pi f_{0} x+\phi(x, y, t)\right]+\frac{1}{2} b(x, y) \exp \left\{-i\left[2 \pi f_{0} x+\phi(x, y, t)\right]\right\}
$$

A Gaussian band-pass filter was applied to obtain the phase distribution. After taken two-dimensional Fourier transform, band-pass filtering and inverse Fourier transform the image $I(x, y, t \text {, })^{\prime}$ can be written in the following form:

$$
I(x, y, t)^{\prime}=\frac{1}{2} b(x, y) \exp i\left[2 \pi f_{0} x+\phi(x, y, t)\right]
$$

Then, the phase difference $\varnothing(x, y)$ between the any time points $t_{1}$ and $t_{2}$ could be calculated by [43],

$$
\Delta \phi(x, y)=\arctan \left\{\frac{\operatorname{Im}\left[I\left(x, y, t_{1}\right)^{* *} I\left(x, y, t_{2}\right)^{\prime}\right]}{\operatorname{Re}\left[I\left(x, y, t_{1}\right)^{* *} I\left(x, y, t_{2}\right)^{\prime}\right]}\right\}
$$

Generally, the phase change between two frames ( 0.04 second interval) is less than $2 \pi$. Meanwhile, phase differences greater than $2 \pi$ give rise to an indeterminacy that can be resolved by use of standard phase-unwrapping methods. In the experiment, the minimal phase difference detected effectively was about $0.1 \mathrm{rad}$. The distribution of the difference of the OPL can be obtained from Equation 2 and the minimal difference of the OPL is about $10 \mathrm{~nm}$. 


\section{Results and Discussion}

During the electrochemical reactions, the concentration of iron ions might change with the time. The OPL difference $\Delta L_{(x, y)}$ obtained from the interferograms, which is the sum of the OPL difference caused by the soluble species dissolved from the iron electrode, can sense the change of dynamic concentration changes and display the occurrence of corrosion processes of the electrode during the reactions. The area in which the OPL changes indicates the location at which the corrosion occurs. The distributions of the OPL difference $\Delta L_{(x, y)}$ can reflect the corrosion processes during any intervals.

Figure 4 shows potentiodynamic sweep curve of iron in $0.5 \mathrm{M} \mathrm{Na}_{2} \mathrm{SO}_{4}$ solution at $10 \mathrm{mV} \cdot \mathrm{s}^{-1}$. It is widely accepted that general corrosion occurs during the polarization processes of $\mathrm{Fe} / 0.5 \mathrm{M} \mathrm{Na}_{2} \mathrm{SO}_{4}$ system. As illustrated in Figure 4, the current increases quickly with the increase in potential at the initial, and reaches a peak when the film is finally formed on the surface of the electrode. After the current peak, the iron electrode enters the passive region.

Figure 4. Potentiodynamic polarization curve of the iron electrode in $0.5 \mathrm{M} \mathrm{Na}_{2} \mathrm{SO}_{4}$ solution at $10 \mathrm{mV} \cdot \mathrm{s}^{-1}$.

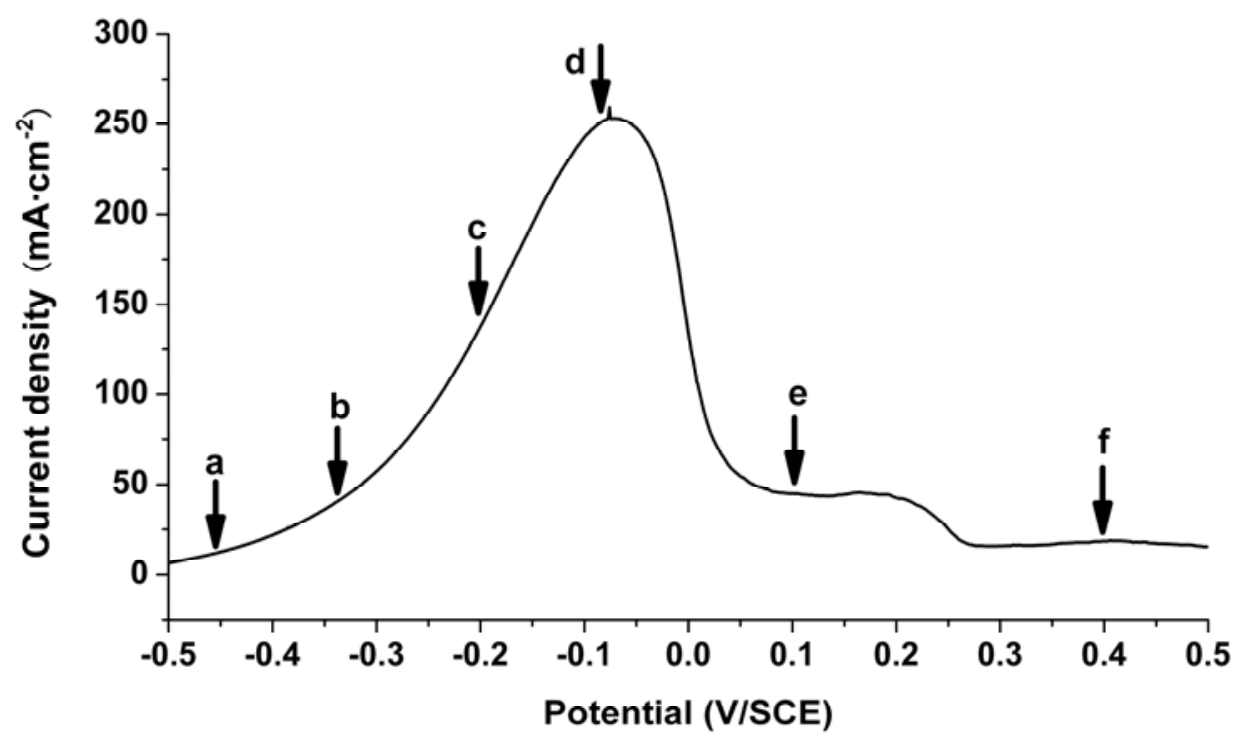

The distribution of the OPL difference in comparison with the starting time during the reaction corresponding to the points a-f in Figure 4 are shown in Figure 5(a-f), respectively. The left parts are the solutions while the rights are the electrodes. Parts in between are the interfaces. The color variation appears evidently at the interface, where turning yellow means the increase of the OPL while turning red means the sharp increase. The larger the value of the OPL is, the more evident the color shows. The green area in those figures indicates that the difference of OPL is nearly constant. Since there is nearly no change at the interface in Figure 5(a), the parts corresponding to the electrolyte, electrode, and interface have been indicated in Figure 5(a) so they can be read more easily. The locations of the interfaces in Figure 5(b-f) are the same as Figure 5(a). This also applies for Figure 7. As can be seen, a yellow color appears only at the interface, showing that the OPL was rather stable in most of the bulk solution, but it increases at the metal/solution interface, which indicated the iron electrode dissolved as 
ions during the reactions. At points $a$ and $b$, the change of the OPL was hardly detectable when the current density is relatively small, as shown in Figure 5(a,b). respectively. As time goes on, the OPL increases at points $\mathrm{c}$ and $\mathrm{d}$ (Figure $5(\mathrm{c}, \mathrm{d})$ ), indicating the concentration of metal ions increases sharply when the current density grows up. The concentration decreases when the density drops (Figure 5(e,f)). Since the OPL distribution is nearly uniform, there is an approximate one-dimensional mass transport at the metal/solution interface, which is consistent with the general corrosion processes of iron in $\mathrm{Na}_{2} \mathrm{SO}_{4}$ solution.

Figure 5. The distributions of the OPL difference at different times in comparison with the initial time during the process of the iron electrode in $0.5 \mathrm{M} \mathrm{Na}_{2} \mathrm{SO}_{4}$ solution at $10 \mathrm{mV} \cdot \mathrm{s}^{-1}$.

(a)

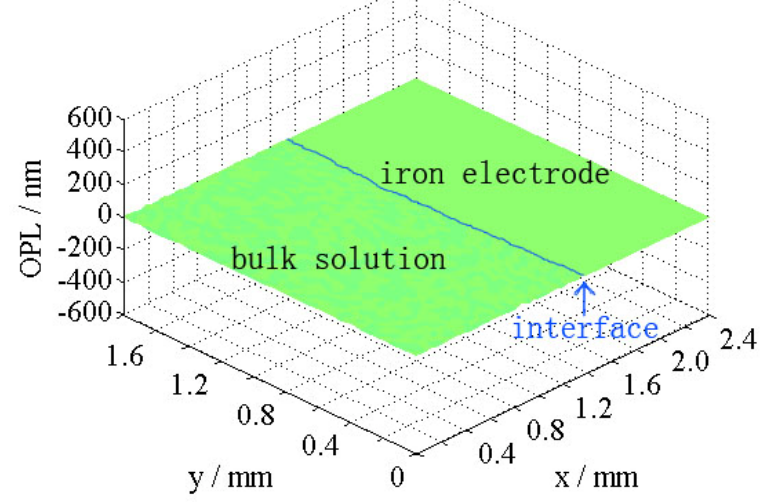

(c)

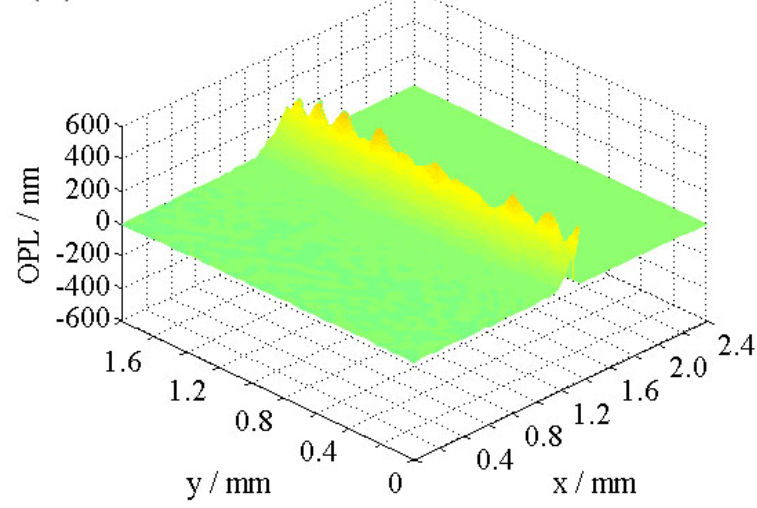

(e)

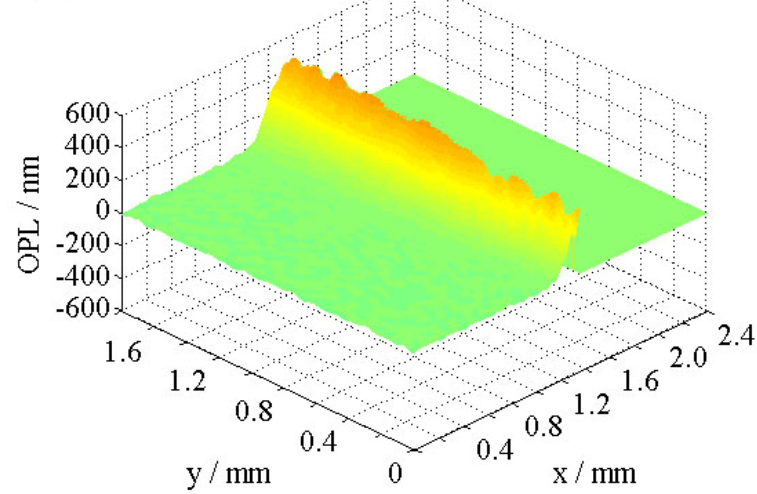

(b)

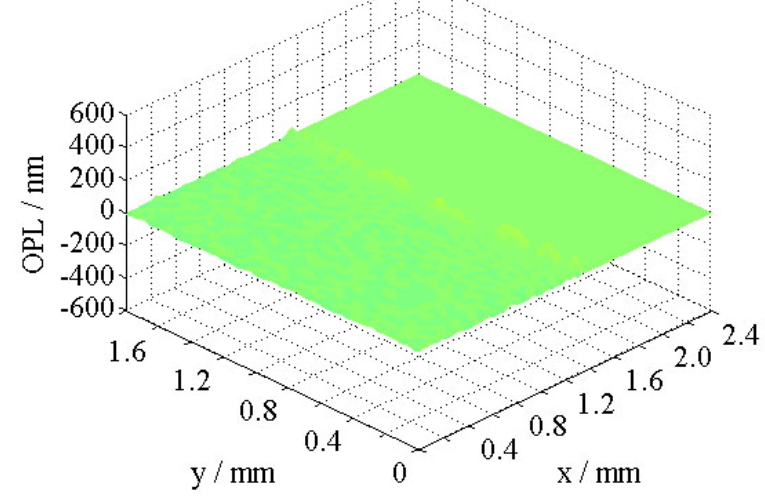

(d)

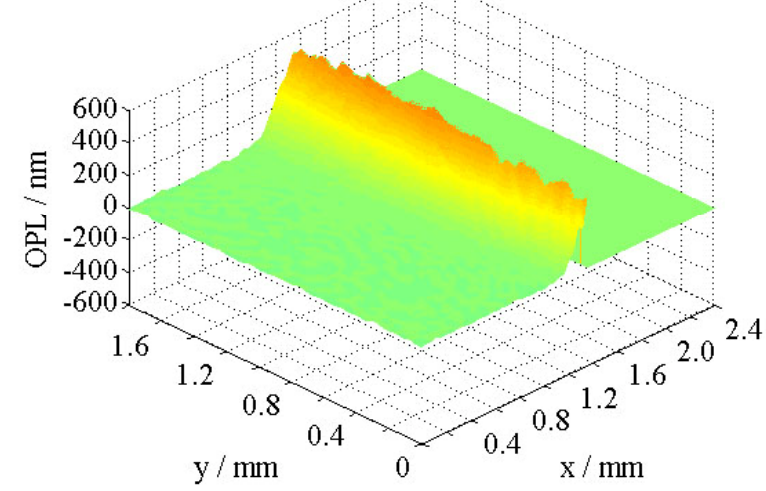

(f)

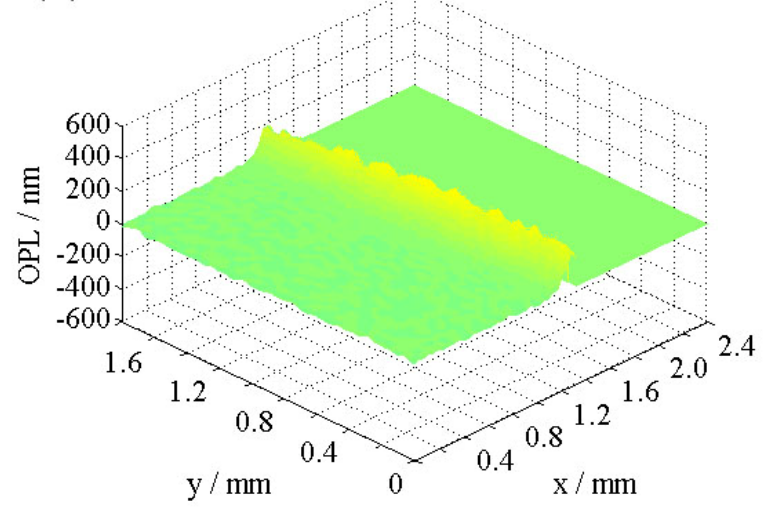


The potentiodynamic sweep curve of the iron electrode in $0.5 \mathrm{M} \mathrm{NaCl}$ solution at $10 \mathrm{mV} \cdot \mathrm{s}^{-1}$ is illustrated in Figure 6. It is widely accepted that localized corrosion appears in aggressive environments, especially in media containing chloride ions. When the potential is more positive than $-0.20 \mathrm{~V} v s$. SCE, the current evidently grows up with the increase of potential. Figure 7 displays the distributions of the difference of OPL at the time points in Figure 6. At the initial of the sweep, the concentration change at the interface is hardly detectable (Figure 7(a)). With the increase of the current density, the appearance of a yellow area in Figure 7(b) indicates that the formation of $\mathrm{Fe}^{2+}$ ions increases the OPL at the local area, and localized corrosion appears at the iron/solution interface. In Figure 7(c), the former yellow area enlarges and another yellow area appears which can be seen more clearly in Figure $7(\mathrm{~d}, \mathrm{e})$. In contrast to the one-dimensional mass transport of general corrosion in $\mathrm{Na}_{2} \mathrm{SO}_{4}$ solution, localized corrosion of the iron electrode formed under the presence of chloride ions. As time goes on, the OPL becomes larger and larger (Figure 7(e,f)). Many more metal ions have been produced and transported out. The whole iron electrode becomes active and the distribution of the OPL difference becomes more uniform at the metal/solution interface (Figure 7(f)).

The thickness of diffusion layer can be visually presented in the OPL distributions. In the case of the potentiodynamic sweep of the iron electrode in $0.5 \mathrm{M} \mathrm{Na}_{2} \mathrm{SO}_{4}$, the thickness of diffusion layer increased with the rise of the current density, and then decreased with the drop. In $0.5 \mathrm{M} \mathrm{NaCl}$, the diffusion layer at the iron/solution interface was not uniform when the localized corrosion appeared. Compared to published work of the authors [11], the results presented here are more revealing. Moreover, digital interferograms are processed automatically to realize consecutive observation of corrosion processes and the dynamic changes of OPL are quantitatively measured to provide a direct evidence of localized corrosion.

Figure 6. Potentiodynamic polarization curve of the iron electrode in $0.5 \mathrm{M} \mathrm{NaCl}$ solution at $10 \mathrm{mV} \cdot \mathrm{s}^{-1}$.

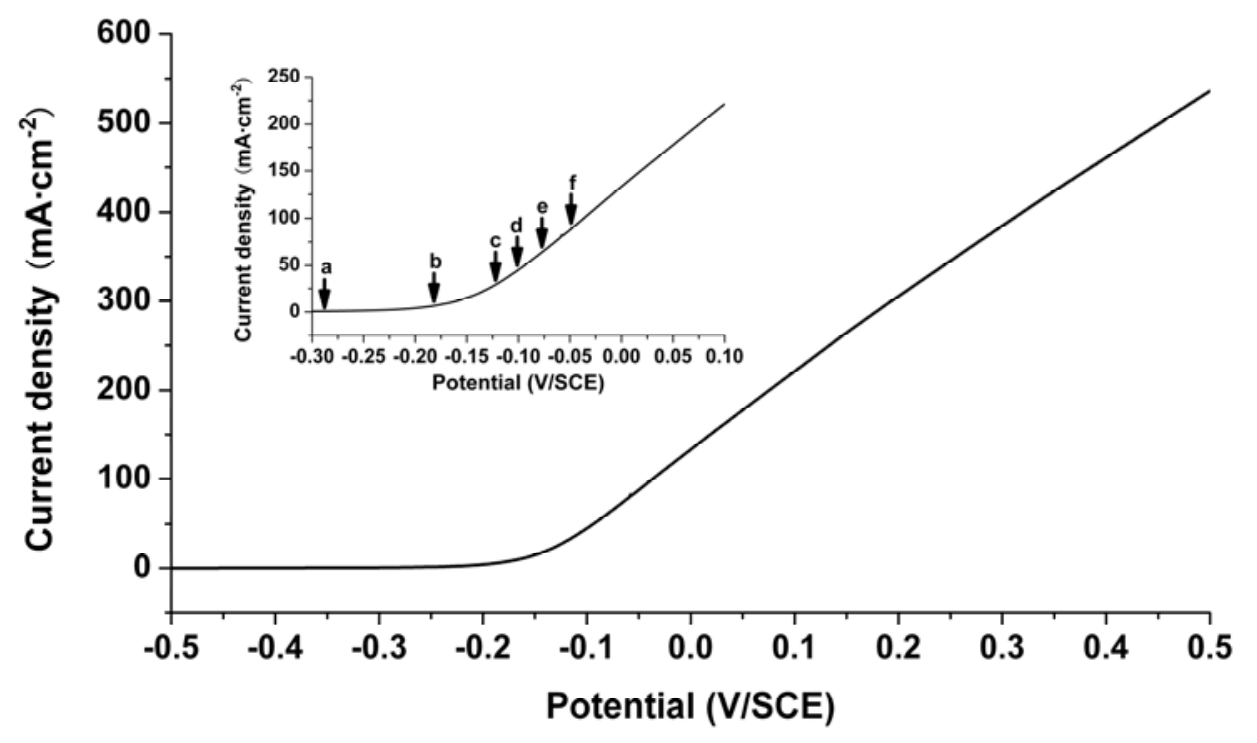


Figure 7. The distributions of the OPL difference at different times in comparison with the initial time during the process of the iron electrode in $0.5 \mathrm{M} \mathrm{NaCl}$ solution at $10 \mathrm{mV} \cdot \mathrm{s}^{-1}$.

(a)

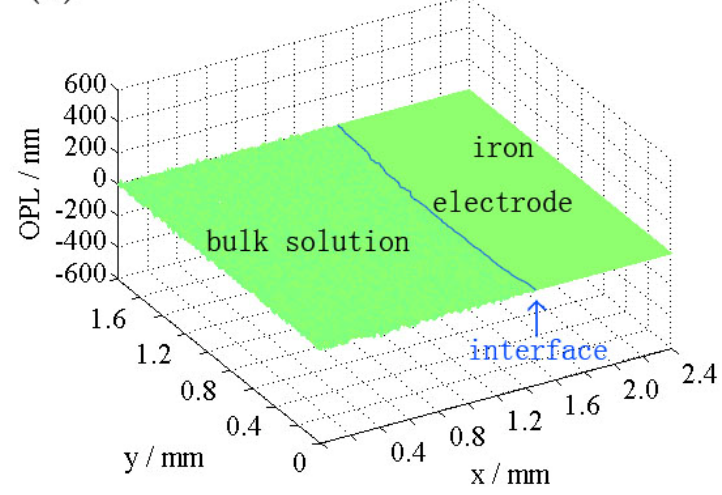

(c)

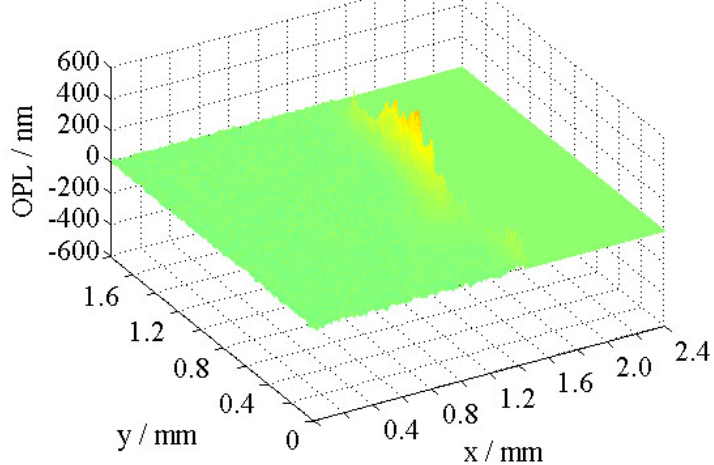

(e)

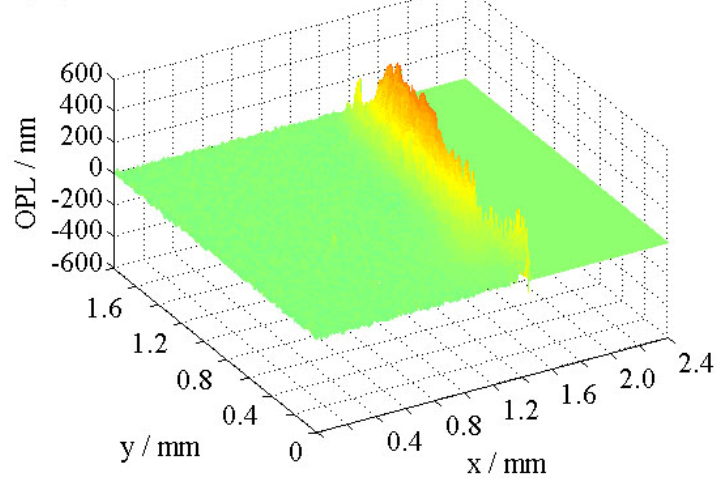

(b)

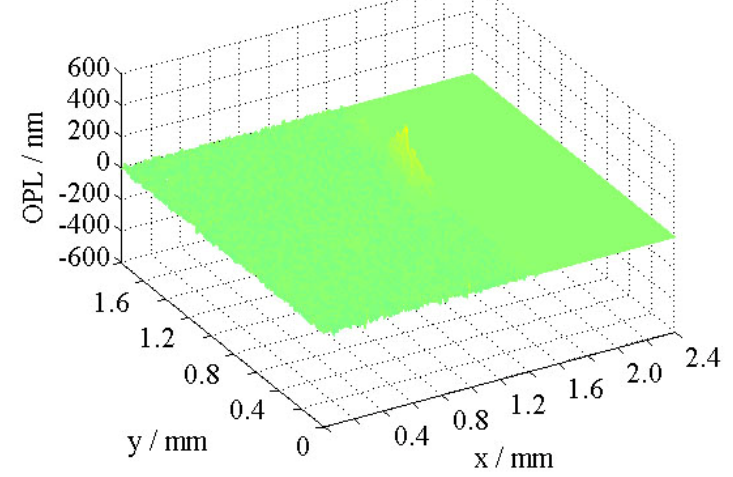

(d)

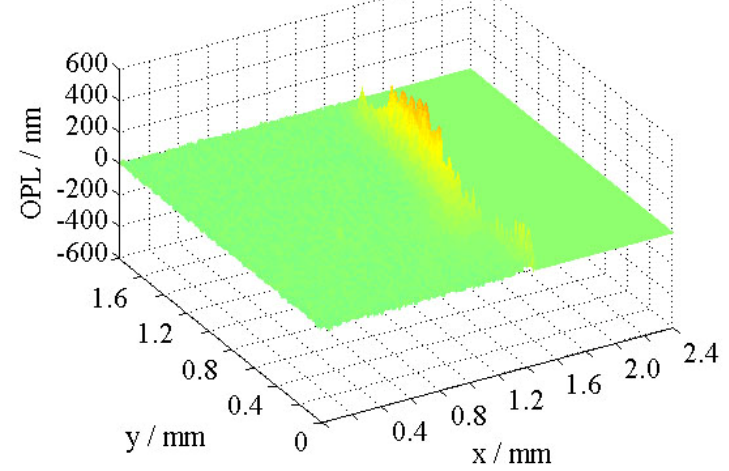

$(\mathrm{f})$

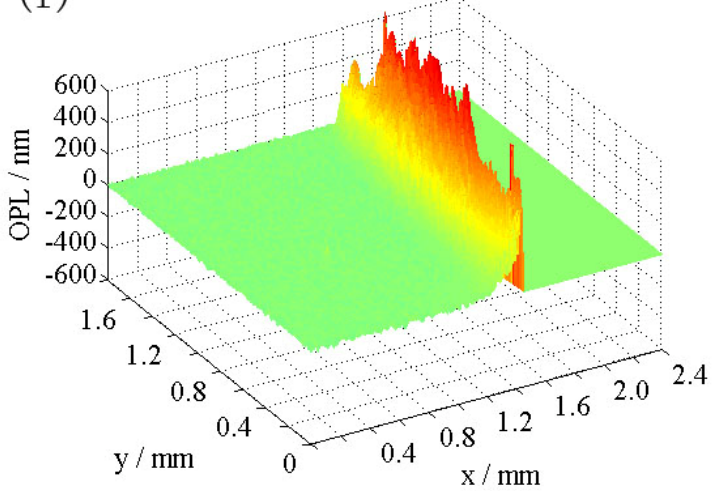

\section{Conclusions}

A Mach-Zehnder interferometer has been employed to visualize the localized processes at the metal/solution during the electrochemical process. In the case of the potentiodynamic sweep of the iron electrode in $0.5 \mathrm{M} \mathrm{Na}_{2} \mathrm{SO}_{4}$ and $0.5 \mathrm{M} \mathrm{NaCl}$ solutions, the distributions of the OPL difference show general and localized corrosion during the electrochemical reactions, respectively. The changes of OPL in the object beam can help capture otherwise inconspicuous information in specimens for quantitative measurement. This method can detect a minimal OPL difference of about $10 \mathrm{~nm}$ caused by the electrochemical reactions. It is proved to be sensitive enough to detect localized corrosion at the metal/solution interface. Although its maximum transverse resolution is confined by diffraction limits, 
it can provide in situ observation of the dynamic processes and study localized corrosion in micro-scale systems. It can reflect the corrosion rate but cannot provide the number and distribution of pits. Further efforts will be made to obtain the quantitative measurement of corrosion rate.

\section{Acknowledgements}

The authors thank Jiangsu Key Technology R\&D Program (BE2010043), the Chinese National Science Fund (No. 21073153 and No. 21173180), the foundation of the Natural Science Foundation (No. 11KJB510025) of Jiangsu Education Committee of China, PAPD of Jiangsu Higher Education Institutions, Jiangsu Qing-Lan Project (10QLD005), Key Laboratory of Colloid and Interface Chemistry (Shandong University) (201001) and Ministry of Education and Key Laboratory of Environmental Material and Environmental Engineering of Jiangsu Province (K090034) for support of this research.

\section{References}

1. Kaesche, H. Corrosion of Metals: Physicochemcial Principles and Current Problems; Springer-Verlag: Berlin/Heidelberg, Germany, 2003.

2. Sazou, D.; Pagitsas, M. Nitrate ion effect on the passive film breakdown and current oscillations at iron surfaces polarized in chloride-containing sulfuric acid solutions. Electrochim. Acta 2002, 47, 1567-1578.

3. Pagitsas, M.; Sazou, D. Current oscillations induced by chlorides during the passive-active transition of iron in a sulfuric acid solution. J. Electroanal. Chem. 1999, 471, 132-145.

4. Sazou, D.; Diamantopoulou, A.; Pagitsas, M. Chemical perturbation of the passive-active transition state of $\mathrm{Fe}$ in a sulfuric acid solution by adding halide ions. Current oscillations and stability of the iron oxide film. Electrochim. Acta 2000, 45, 2753-2769.

5. Szklarska-Smialowska, Z. Mechanism of pit nucleation by electrical breakdown of the passive film. Corros. Sci. 2002, 44, 1143-1149.

6. Punckt, C.; Bolscher, M.; Rotermund, H.H.; Mikhailov, A.S.; Organ, L.; Budiansky, N.; Scully, J.R.; Hudson, J.L. Sudden onset of pitting corrosion on stainless steel as a critical phenomenon. Science 2004, 305, 1133-1136.

7. Leung, C.K.Y.; Wan, K.T.; Chen, L.Q. A novel optical fiber sensor for steel corrosion in concrete structures. Sensors 2008, 8, 1960-1976.

8. Pereira, E.V.; Figueira, R.B.; Salta, M.M.L.; Fonseca, I.T.E. A galvanic sensor for monitoring the corrosion condition of the concrete reinforcing steel: relationship between the galvanic and the corrosion currents. Sensors 2009, 9, 8391-8398.

9. Zhao, X.F.; Gong, P.; Qiao, G.F.; Lu, J.; Lv, X.J.; Qu, J.P. Brillouin corrosion expansion sensors for steel reinforced concrete structures using a fiber optic coil winding method. Sensors 2011, 11, 10798-10819.

10. Wang, C.; Chen, S.H.; Yang, X.G.; Li, L. Investigation of chloride-induced pitting processes of iron in the $\mathrm{H}_{2} \mathrm{SO}_{4}$ solution by the digital holography. Electrochem. Commun. 2004, 6, 1009-1015.

11. Li, L.; Wang, C.; Chen, S.H.; Yang, X.G.; Yuan, B.Y.; Jia, H.L. An investigation on general corrosion and pitting of iron with the in-line digital holography. Electrochim. Acta 2008, 53, 3109-3119. 
12. Emad, A.A.; Meguid, E. Progress in Corrosion Research. Localized Corrosion of Stainless Steel; Nova Science Publishers, Inc.: Hauppauge, NY, USA, 2007; Chapter 8, pp. 261-299.

13. Landolt, D. Corrosion and Surface Chemistry of Metals; EPFL Press: Lausanne, Switzerland, 2007; pp. 192-206.

14. Fernandes, J.C.S.; Ferreira, M.G.S. Effect of carbonate and lithium ions on the corrosion performance of pure aluminium. Electrochim. Acta 1992, 37, 2659-2661.

15. Kearns, J.R.; Scully, J.R.; Roberge, P.R.; Reichert, D.L.; Dawson, J.L. Electrochemical Noise Measurement for Corrosion Applications; ASTM STP 1277, American Society for Testing and Materials: West Conshohocken, PA, USA, 1996; pp. 101-103, 307-342.

16 Tan, Y.J. Sensing localised corrosion by means of electrochemical noise detection and analysis. Sens. Actuators B Chem. 2009, 139, 688-698.

17. Kolics, A.; Besing, A.S.; Baradlai, P.; Haasch, R.; Wieckowski, A. Effect of pH on thickness and ion content of the oxide film on Aluminum in $\mathrm{NaCl}$ media. J. Electrochem. Soc. 2001, 148, B251-B259.

18. Natishan, P.M.; O’Grady, W.E.; Martin, F.J.; Rayne, R.J.; Kahn, H.; Heuer, A.H. Chloride interactions with the passive films on stainless steel. J. Electrochem. Soc. 2011, 158, C7-C10.

19. Abreu, C.M.; Cristobal, M.J.; Figueroa, R.; Pena, G. Influence of molybdenum ion implantation on the localized corrosion resistance of a high strength aluminium alloy. Corros. Sci. 2012, 54, $143-152$.

20. Tang, X.; Cheng, Y.F. Quantitative characterization by micro-electrochemical measurements of the synergism of hydrogen, stress and dissolution on near-neutral $\mathrm{pH}$ stress corrosion cracking of pipelines. Corros. Sci. 2011, 53, 2927-2933.

21. Jin, T.Y.; Cheng, Y.F. In situ characterization by localized electrochemical impedance spectroscopy of the electrochemical activity of microscopic inclusions in an X100 steel. Corros. Sci. 2011, 53, 850-853.

22. Liao, J.S.; Kishimoto, K.; Yao, M.; Mori, Y.; Ikai, M. Effect of ozone on corrosion behavior of mild steel in seawater. Corros. Sci. 2012, 55, 205-212.

23. Davoodi, A.; Pan, J.; Leygraf, C.; Norgren, S. Probing of local dissolution of Al-alloys in chloride solutions by AFM and SECM. Appl. Surf. Sci. 2006, 252, 5499-5503.

24. Davoodi, A.; Pan, J.; Leygraf, C.; Norgren, S. Integrated AFM and SECM for in situ studies of localized corrosion of Al alloys. Electrochim. Acta 2007, 52, 7697-7705.

25. Yin, Y.; Niu, L.; Lu, M.; Guo, W.K.; Chen, S.H. In situ characterization of localized corrosion of stainless steel by scanning electrochemical microscope. Appl. Surf. Sci. 2009, 255, 9193-9199.

26. Liu, Z.Y.; Li, X.G.; Cheng, Y.F. In-situ characterization of the electrochemistry of grain and grain boundary of an X70 steel in a near-neutral pH solution. Electrochem. Commun. 2010, 12, 936-938.

27. Bastos, A.C.; Taryba, M.G.; Karavai, O.V.; Zheludkevich, M.L.; Lamaka, S.V.; Ferreira, M.G.S. Micropotentimetric mapping of local distributions of $\mathrm{Zn}^{2+}$ relevant to corrosion studies. Electrochem. Commun. 2010, 12, 394-397.

28. Kallip, S.; Bastos, A.C.; Zheludkevich, M.L.; Ferreira, M.G.S. A multi-electrode cell for high-throughput SVET screening of corrosion inhibitors. Corros. Sci. 2010, 52, 3146-3149. 
29. Marquet, P.; Rappaz, B.; Magistretti, P.J.; Cuche, E.; Emery, Y.; Colomb, T.; Depeursinge, C. Digital holographic microscopy: A noninvasive contrast imaging technique allowing quantitative visualization of living cells with subwavelength axial accuracy. Opt. Lett. 2005, 30, 468-470.

30. Lazar, J.; Cip, O.; Cizek, M.; Hrabina, J.; Buchta, Z. Suppression of air refractive index variations in high-resolution interferometry. Sensors 2011, 11, 7644-7655.

31. Anand, A.; Chhaniwal, V.K.; Narayanamurthy, C.S. Diffusivity studies of transparent liquid solutions by use of digital holographic interferometry. Appl. Opt. 2006, 45, 904-909.

32. Habib, K.; Al-Muhana, K.; Habib, A. Holographic interferometry as electrochemical emission spectroscopy of carbon steel in seatater with low concentration of RA-41 corrosion inhibitor. Opt. Laser Technol. 2008, 46, 149-156.

33. Wang, M.F.; Li, X.G.; Du, N.; Huang, Y.Z.; Korsunsky, A. Derect evidence of initial pitting corrosion. Electrochem. Commun. 2008, 10, 1000-1004.

34. Tada, E.; Kaneko, H. Optical visualiztion of concentration field of $\mathrm{Zn}^{2+}$ during galvanic corrosion of a $\mathrm{Zn} /$ steel couple. Corros. Sci. 2010, 52, 3421-3427.

35. Li, L.; Wang, C.; Yuan, B.Y.; Chen, S.H. Numerical reconstrution of digital holograms for the study of pitting dynamic processes of the X70 carbon steel in $\mathrm{NaCl}$ solution. Electrochem. Commun. 2008, 10, 103-107.

36. Yuan, B.Y.; Chen, S.H.; Yang, X.G.; Wang, C.; Li, L. Mapping the transient concentration field within the diffusion layer by use of the digital holographic reconstruction. Electrochem. Commun. 2008, 10, 392-396.

37. Jia, H.L.; Chen, S.H.; Yuan, B.Y.; Wang, C.; Li, L. Mapping the contration changes during the dynamic processes of crevice corrosion by digital holographic reconstruction. J. Serb. Chem. Soc. 2009, 74, 197-202.

38. Yuan, B.Y.; Wang, C.; Li, L.; Chen, S.H. Real time observation of the anodic dissolution of copper in $\mathrm{NaCl}$ solution with the digital holography. Electrochem. Commun. 2009, 11, 1373-1376.

39. Wang, L.; Chen, S.H.; Yuan, B.Y.; Meng, F.J.; Wang, J.Q.; Wang, C.; Li, L. Digital holographic reconstruction detection of localized corrosion arising from scratches. J. Serb. Chem. Soc. 2010, 75, 505-512.

40. Yuan, B.Y.; Wang, C.; Li, L.; Chen, S.H. Investigation of the effects of the magnetic field on the anodic dissolution of copper in $\mathrm{NaCl}$ solution with holography. Corros. Sci. 2012, 58, 69-78.

41. Born, M.; Wolf, E. Principles of Optics, 7th (expanded) ed.; The United Kingdom at the University Press: Cambridge, UK, 1999; p. 286.

42. Muller, R.H. Advances in Electrochemistry and Electrochemical Engineering. Double Beam Interferometry for Electrochemical Studies; John Wiley \& Sons, Inc: Hoboken, NJ, USA, 1973; Volume 9, p. 282.

43. Quan, C.; Shang, H.M.; Bryanston-Cross, P.J. Application of the holographic carrier fringe and FFT technique for deformation measurement. Opt. Laser Technol. 1996, 28, 7-13.

(C) 2012 by the authors; licensee MDPI, Basel, Switzerland. This article is an open access article distributed under the terms and conditions of the Creative Commons Attribution license (http://creativecommons.org/licenses/by/3.0/). 